\title{
Experimental Study of Temperature Effect on Human Skin: Discussion of Methodology
}

\author{
Ahmad Rasdan Ismail ${ }^{1, a}$, Rosli Abu Bakar ${ }^{2, b}$ and Norfadzilah Jusoh ${ }^{2, c}$ \\ ${ }^{1}$ Faculty of Technology, Univeristi Malaysia Pahang, 26300 Gambang, Pahang, Malaysia \\ ${ }^{2}$ Faculty of Mechanical Engineering, Universiti Malaysia Pahang, 22600 Pekan, Pahang, Malaysia \\ aarasdan@gmail.com, brosli@ump.edu.my, cjnfadzilah@gmail.com
}

Keywords: Comfort, physiology, skin temperature, thermal.

\begin{abstract}
This paper present the discussion of methods used in experimental studies of thermal comfort that only focus on the effect skin temperature of human. The study was conducted human subject tests in a controlled environment chamber for cooling conditions. This study was measure in the test climate chamber at Universiti Malaysia Pahang. Three broad methodology categories are compared which are experiments in which subjects have control of air temperature, relative humidity or neither. The local supply air temperatures were at 19,25 and $32{ }^{\circ} \mathrm{C}$ while relative humidity was at 40, 55 and $70 \%$. Together with a previously proposed diagram of basic features of the human thermoregulatory system may be used to specify limits for air temperature and relative humidity in the indoor environment.
\end{abstract}

\section{Introduction}

Previous studies [1,2] have reported that the climate of Malaysia is hot and humid with the average of temperature is between $23.7{ }^{\circ} \mathrm{C}$ to $31.3{ }^{\circ} \mathrm{C}$ all the day with the highest maximum temperature recorded at $36.9{ }^{\circ} \mathrm{C}$ and the average of humidity between $67 \%$ to $95 \%$ and these factors give an impact on occupant comfort indoor the building.

Over the last ten years thermal comfort research has gone extensively under a new wave of development methods and concepts. Thermal comfort is defined state of mind at which is expresses satisfaction with the surrounding thermal environment [3]. Thermal comfort is much more related with the human indoor building. Using air conditioning in the building is a trend nowadays in Malaysia. Song et al. [4] analyzed that the room temperature in air conditioned environments depend on the air conditioning system's setting which is influenced by energy policy and the system's design and maintenance. ASHRAE-IEC Standard 90.1 [5] recommends an air temperature of 24-26 ${ }^{\circ} \mathrm{C}$ for cooling. However, ISO 7730 [6] and ASHRAE [3], have suggested the comfortable temperature range is described as being in range of $18-28{ }^{\circ} \mathrm{C}$. In 1995 , Nicol et al. [7] reported the preferable indoor temperature for thermal comfort varies according to cultural habits, race, location and according Parson [8] consists individual activity and clothing insulation value.

Human physiological (thermoregulation) system has been the focus of thermal comfort research since the early 1960's. Physiological models were developed to predict the responses of human body under different indoor environment.

\section{Background Study}

More psychologists stated that brain influence to skin temperature. A surroundings response such as a change in skin temperature can be used as an indicator of brain activity or state of mind. Skin temperature depends on three of factors [9]:

i. Environmental conditions (clothing, environmental temperature, humidity and circulation of air)

ii. Individual variables such as genetics, gender and health

iii. Cognitive/emotional or psychological states 
The ability to maintain a constant body temperature is one of the main characteristics in mammals and which makes us different from cold blooded animals. Mammals have developed the means of adaptation to different environments. Particularly interesting is the case of humans and their behavioral adaptation such as the use of clothing and indoor climate control systems. Hence, thermoregulation system and reaction of human body to different environments, both physiological such as skin and core temperature and psychological which are thermal sensation and thermal comfort are of great interest to biologist and indoor climate engineers.

\section{Material and Methods}

Laboratory methods utilize a wide array of possible physical and subjective measures. The basic measurements needed in experiments involving human comfort are air temperature, humidity and some subjective measure of the thermal state of the subject. Several study from the previous collected extensive skin and core temperature data directly. Some studies concentrated on a portion of the comfort zone, while others attempted to measure throughout the entire zone. Measurements of air temperature were typically made by thermocouples, while humidity was measure with hot wire/bulb. The interval for physical measurements on the body was typically every 10 minutes, while physical environmental measurements varied from many times per second to every 10 minutes.

Facility. The experiments were carried out in a controlled environment chamber at Universiti Malaysia Pahang. The chamber's air temperature and relative humidity were controlled automatically and the accuracy controls were $\pm 0.5{ }^{\circ} \mathrm{C}$ and $\pm 5 \%$. Fig. 1 present test climate chamber as a case study. There was which the workstation environment is, Fig. 1a show the floor plan of climate chamber, while Fig. 1b show the front elevation of climate chamber. In the workstation, table, chair, laptop and books were added to create an office atmosphere. The ventilation method in the climate chamber had a ceiling supply and floor return. The chamber was a closed space in the basement without sunlight coming through the windows and other radiant sources.

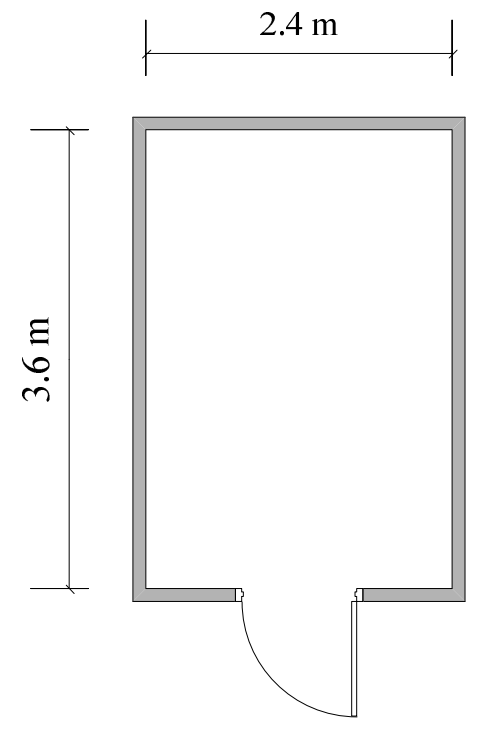

a. Floor Plan
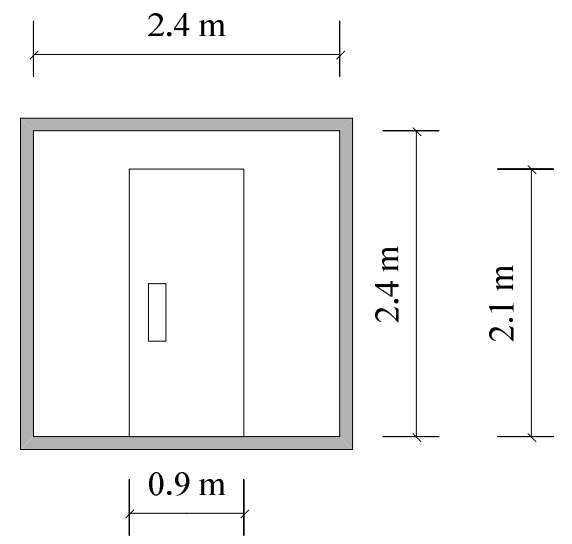

b. Front Elevation

Fig. 1, Test climate chamber layout of the study

This study focused on human comfort at different air temperature and relative humidity as illustrated in Table 1. The impact of air temperature and relative humidity on perception or thermal sensation of effect on skin subject at three level of air temperature and relative humidity as shown in Table 1. There are three level of air temperature which is 19,25 and $32{ }^{\circ} \mathrm{C}$, also relative humidity which are 40, 55 and 70\%. A large, comfort and cold of temperature was used in the measurement. 
Level of skin temperature of human was obtained for lower temperature/lower relative humidity and so on according Table 1.

Table 1, Parameters control during measurement in the climate chamber

\begin{tabular}{|c|c|c|}
\hline & $\begin{array}{c}\text { Air } \\
\text { Temperature } \\
\left({ }^{\circ} \mathbf{C}\right)\end{array}$ & $\begin{array}{c}\text { Relative } \\
\text { Humidity } \\
(\text { RH) }\end{array}$ \\
\hline 1 & 19.0 & 40 \\
\hline 2 & 19.0 & 55 \\
\hline 3 & 19.0 & 55 \\
\hline 4 & 19.0 & 70 \\
\hline 5 & 25.5 & 40 \\
\hline 6 & 25.5 & 55 \\
\hline 7 & 25.5 & 55 \\
\hline 8 & 25.5 & 55 \\
\hline 9 & 25.5 & 40 \\
\hline 10 & 25.5 & 70 \\
\hline 11 & 25.5 & 70 \\
\hline 12 & 32.0 & 55 \\
\hline 13 & 32.0 & 70 \\
\hline 14 & 32.0 & 55 \\
\hline 15 & 32.0 & 40 \\
\hline
\end{tabular}

\section{Discussion}

During normal rest or activity, the heat transfer processes result in average vital organ temperature near $37{ }^{\circ} \mathrm{C}$. According Hensel [10] the human thermoregulatory system is more complicated and incorporates more control principles than any actual technical control system. Fig. 2 presents some basic features of the human thermoregulatory system. Findings from Djongyang et al. [11] stated that, the controlled variable is an integrated value of internal temperature which is near the central nervous system and other deep body temperatures and skin temperature. The controlled system is influenced by internal (internal heat generation by exercise) and external (originating from environmental heat or cold) thermal disturbances. External thermal disturbances are rapidly detected by thermoreceptors in the skin. This enables the thermoregulatory system to act before the disturbances reach the body core.

Hensen [12] found that autonomic thermoregulation is controlled by the hypothalamus. There are different autonomic control actions such as adjustment of: heat production (by shivering), internal thermal resistance (by vasomotion; such as control of skin blood flow), external thermal resistance (control by of respiratory dry heat loss), water secretion and evaporation (by sweating and respiratory evaporative heat loss). The associated temperature for these autonomic control actions need not necessarily be identical nor constant or dependent on each other. 


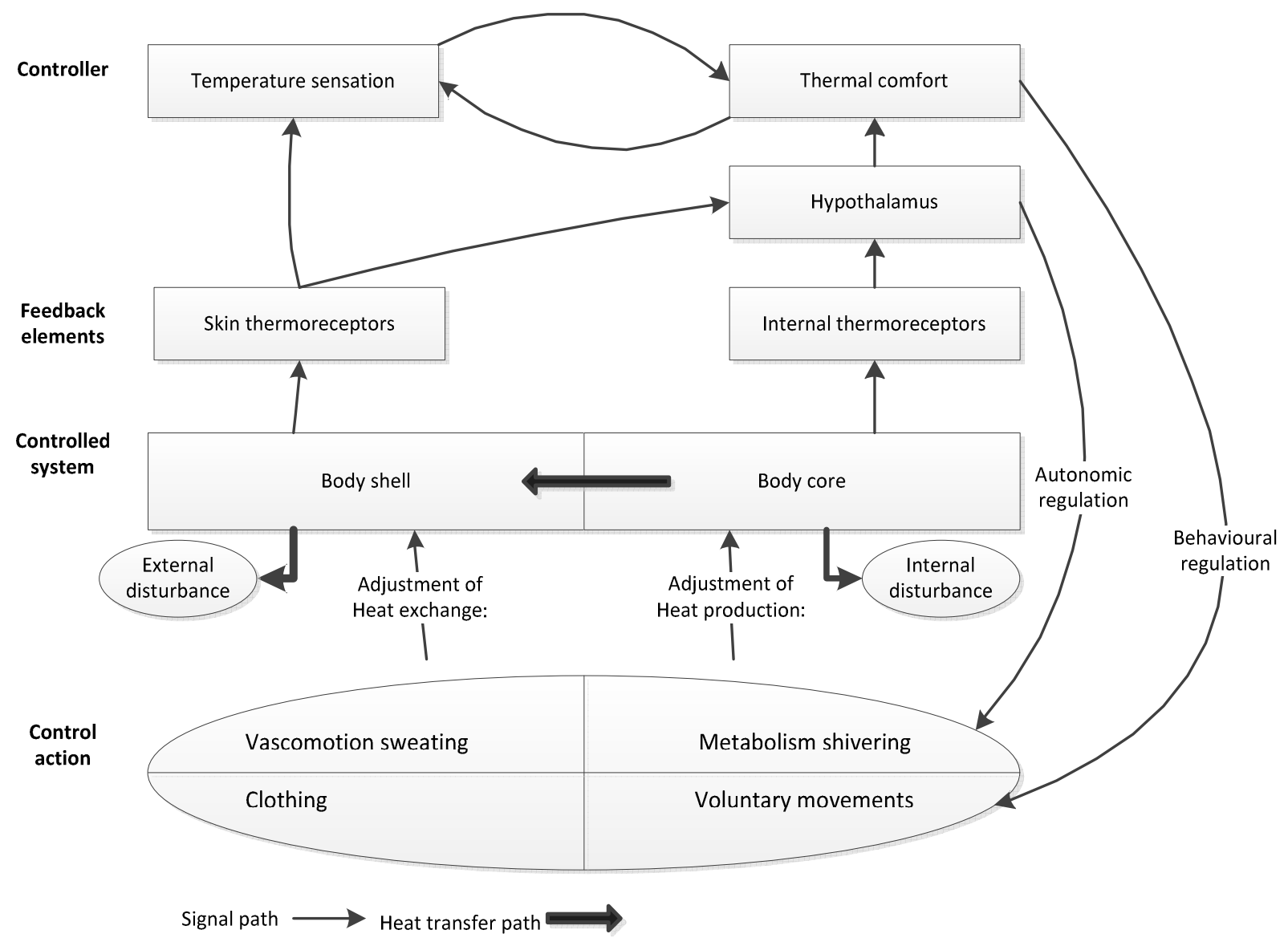

Fig. 2, Schematic diagram of autonomic and behavioral human temperature regulation [10]

A practical approach is therefore to consider heat production within the body $(M-W)$, heat loss at the skin $\left(C+R+E_{s k}\right)$ and the heat loss due to respiration $\left(C_{r e s}+E_{r e s}\right)$ [8].

Heat loss at the skin $\left(\boldsymbol{C}+\boldsymbol{R}+\boldsymbol{E}_{\text {sk }}\right)$. Sensible heat loss $(R+C)[13]$ :

$$
\begin{aligned}
& C=f_{c l} h_{c}\left(t_{c l}-t_{a}\right) \\
& R=f_{c l} h_{r}\left(t_{c l}-t_{r}\right) \\
& C+R=f_{c l} h\left(t_{c l}-t_{o}\right)
\end{aligned}
$$

where,

$$
t_{o}=\frac{\left(h_{r} t_{r}+h_{c} t_{a}\right)}{h_{r}+h_{c}} \text { and } h=h_{r}+h_{c}
$$

$f_{c l}=$ clothing area factor. The surface area of the clothed body $A_{c l}$, divided by the surface area of the nude body $A_{D}$ $h_{c}=$ convective heat transfer coefficient $\left(\mathrm{Wm}^{-2} \mathrm{~K}^{-1}\right)$

$h_{r}=$ linear radiative heat transfer coefficient $\left(\mathrm{Wm}^{-2} \mathrm{~K}^{-1}\right)$

$h=$ combined heat transfer coefficient $\left(\mathrm{Wm}^{-2} \mathrm{~K}^{-1}\right)$

$t_{o}=$ operative temperature $\left({ }^{\circ} \mathrm{C}\right)$

$t_{r}=$ mean radiant temperature $\left({ }^{\circ} \mathrm{C}\right)$

$t_{a}=$ air temperature $\left({ }^{\circ} \mathrm{C}\right)$

$t_{c l}=$ mean temperature over the clothed body $\left({ }^{\circ} \mathrm{C}\right)$

$t_{s k}=$ mean skin temperature $\left({ }^{\circ} \mathrm{C}\right)$

$R_{c l}=$ thermal resistance of clothing $\left(\mathrm{m}^{2} \mathrm{KW}^{-1}\right)$ 


\section{Evaporative heat loss from the skin $\left(E_{s k}\right)$.}

$$
\begin{gathered}
E_{s k}=\frac{w\left(P_{s k, s}-P_{a}\right)}{\left[R_{e, c l}+\frac{1}{f_{c l} h_{e}}\right]} \\
w=0.06+0.94 \frac{E_{r s w}}{E_{\max }}
\end{gathered}
$$

where,

$P_{a}=$ water vapor pressure in the ambient air $(\mathrm{kPa})$

$P_{s k, s}=$ water vapor pressure at the skin, normally assumed to be that saturated water vapor at skin temperature, $t_{s k}(\mathrm{kPa})$

$R_{e, c l}=$ evaporative heat transfer resistance of the clothing layer $\left(\mathrm{m}^{2} \mathrm{kPaW}^{-1}\right)$

$h_{e}=$ evaporative heat transfer coefficient $\left(\mathrm{Wm}^{-2} \mathrm{kPa}^{-1}\right)$

$w=$ skin wittedness

$h_{e}$ is calculated using the Lewis Relation $h_{e}=L R h_{c}$. This is important development in the establishment of the body heat balance equation allowing comparison and combination of dry and evaporative heat transfer.

Heat loss from respiration $\left(\mathbf{C}_{\text {res }}+\mathbf{E}_{\text {res }}\right)$. Heat loss from respiration is by 'dry' convective heat transfer due to cool air being inhaled, heated to core temperature in the lungs and heat transferred in exhaled air to the environment $\left(C_{r e s}\right)$. In addition, inhaled air is moistened by the lungs. When exhaled, therefore there is a mass (heat) transfer from the body core to the outside environment $\left(E_{\text {res }}\right)[12]$.

$$
C_{r e s}+R_{r e s}=\left[0.0014 M\left(34-t_{a}\right)+0.0173 M\left(5.87-P_{a}\right)\right]
$$

Besides autonomic thermoregulation, there is also behavioral thermoregulation with control actions such as active movement and adjustment of clothing. Behavioral thermoregulation is associated with conscious temperature sensation as well as with thermal comfort or discomfort [12].

The effect of psychological variables on thermal comfort perception is often acknowledged but rarely discussed in detail or controlled in experiments. Another issues not often discussed but implicitly built into most of the experimental designs is the question of local discomfort with whole body discomfort. For example, ceiling fans, diffusers or slotted ceiling produce air currents in the room.

\section{Conclusion}

According the method used in this study of the effect of skin temperature on thermal comfort in previous study [14] suggests some guidelines for obtaining reliable data:

i. Either bring the subject back to neutral after each exposure or keep the subject at neutral the whole time

ii. When keeping in the subject at neutral, vary only a single variable and wait until the subject has again reached neutral using his/her personally adjustable variable before changing the controlled variable

iii. If specific body areas are being tested for sensitivity, results and recommendations should be presented in terms of those particular areas.

Another important issue for future research and standard development is the level of control provided to subjects in the field study and office workers in the field. Further work is to establish air temperature limit for skin temperature comfort, as they are essential component of the standard. 


\section{References}

[1] I. Hussein and M.H.A. Rahman, Field study of thermal in Malaysia, European Journal of Scientific Research. 1 (2009) 134-152.

[2] Q.J. Kwong and N.M. Adam, Thermal comfort in enclosed lift lobby of tropical educational institution, Thammasat Int. J. Sci. Tech. 15 (3) (2010) 8-18.

[3] American Society of Heating, Refrigerating and Air Conditioning Engineers (ASHRAE), ASHRAE Standard 5, Thermal Environmental Conditions for Human Occupancy, 2004.

[4] G.S. Song, J.H. Lim and T.K. Ahn, Air conditioner operation behavior based on student's skin temperature in a classroom, Applied Ergonomics. 43 (2012) 211-216.

[5] ASHRAE-IEC Standard 90.1, Energy standard for buildings except low rise residential buildings, American Society of Heating, Refrigerating and Air Conditioning Engineers, Atlanta, GA, 2007.

[6] ISO 7730, Moderate thermal environment-Determination of PMV and PPD indices and Specifications of conditions of thermal comfort, International Organization for Standardization, Geneva, 1994.

[7] F. Nicol, M. Humphreys, O. Sykeys and S. Roaf, Standard for thermal comfort, E\&FN Spon, London, 1995.

[8] K.C. Parson, Human thermal environments, second ed., Taylor \& Francis, New York, 2003.

[9] Anon, Experiment HP (Human Physiology) skin temperature stress calming and embarrassment, Human Physiology. (2011) 1-11, http://www.docstoc.com/docs/90520741/ Experiment-HP-Skin-Temperature-Stress-Calming-and-Embarrassment.

[10]H. Hensel, Thermoreception and temperature regulation, In: Monographs of the physiological society 38, London: Academic Press, 1981.

[11]N. Djongyang, R. Tchinda and D. Njomo, Thermal comfort: A review, Renewable and Sustainable Energy Reviews. 14 (2010) 2626-2640.

[12]J.L.M. Hensen, On the thermal interaction of building structure and heating and ventilation system, PhD thesis, Technische Universiteit Eindhoven, 1991.

[13] ASHRAE, Thermal comfort. ASHRAE Handbook of Fundamentals, Atlanta, USA, 1997.

[14]M. Fountain, Laboratory studies of the effect of air movement on thermal comfort, ASHRAE Transactions. 97 (1991) 863-873. 